\title{
Effectiveness of a cognitive behavioral intervention in patients with medically unexplained symptoms: cluster randomized trial
}

\author{
Alberto López-García-Franco ${ }^{*}$, Ma . Isabel del-Cura-González²,3, Luis Caballero-Martinez ${ }^{4}$, Teresa Sanz-Cuesta ${ }^{2}$, \\ Marta Isabel Díaz-García ${ }^{5}, M^{a}$. Teresa Rodriguez-Monje ${ }^{6}$, Marcela Chahua ${ }^{7}$, Inmaculada Muñoz-Sanchez ${ }^{8}$, \\ Dolores Serrano-González ${ }^{6}$, Teresa Rollán-Llanderas ${ }^{9}$, Esther Nieto-Blanco ${ }^{10}$, Liliana Losada-Cucco ${ }^{6}$, \\ Fernando Caballero-Martínez ${ }^{11}$, Nuria Sanz-García ${ }^{1}$, Belén Pose-García ${ }^{1}$, Montserrat Jurado-Sueiro ${ }^{12}$, \\ Manuela Luque Rey ${ }^{13}$, Francisca García de Blas González ${ }^{1}$, Ma. Angeles Miguel Abanto ${ }^{13}$, Teresa Sanz Bayona ${ }^{13}$, \\ Rafaela Ayllón-Camargo ${ }^{6}$, Inmaculada Santamaría Lopez ${ }^{6}$, María Luisa Santiago Hernando ${ }^{12}$, \\ Rosario Beltran-Alvarez ${ }^{14}$, Ana Isabel Aguilar-Gutierrez ${ }^{14}$, Jose Luis Mota-Rodriguez ${ }^{14}$, Rafaél Cosculluela-Pueyo ${ }^{14}$, \\ Teresa López-Martín-Aragón ${ }^{13}$, Rosa Bonilla-Sanchez ${ }^{15}$, Ma . Carmen Aritieda-González-Granda ${ }^{15}$, \\ Raquel Razola-Rincón ${ }^{15}, M^{\text {a}}$. Angeles Sanchez-de-la-Ventana ${ }^{16}$, Concepción Martinez-Guinea ${ }^{16}$, Luis Huerta-Galindo ${ }^{16}$, \\ Ana Belén Barrio-Ovalle ${ }^{16}$, Susana Miguel-Martín ${ }^{16}$, Paz Portero-Fraile ${ }^{16}$, Higinio Pensado-Freire ${ }^{17}$, \\ Ma Luisa Herrera-Garcia ${ }^{18}$, Amaya Azcoaga-Lorenzo ${ }^{1}$, Inés Gómez-García ${ }^{19}$, Nuria Llamas-Sandino ${ }^{19}$, \\ Isabel López-Borja ${ }^{19}$, Hortensia Maldonado-Castro ${ }^{19}$, Patricia Lumbreras-Villarán ${ }^{1}$ and Carlos Ascanio-Durán ${ }^{1}$
}

\begin{abstract}
Background: Medically unexplained symptoms are an important mental health problem in primary care and generate a high cost in health services.

Cognitive behavioral therapy and psychodynamic therapy have proven effective in these patients. However, there are few studies on the effectiveness of psychosocial interventions by primary health care. The project aims to determine whether a cognitive-behavioral group intervention in patients with medically unexplained symptoms, is more effective than routine clinical practice to improve the quality of life measured by the SF-12 questionary at 12 month.

Methods/design: This study involves a community based cluster randomized trial in primary healthcare centres in Madrid (Spain). The number of patients required is 242 (121 in each arm), all between 18 and 65 of age with medically unexplained symptoms that had seeked medical attention in primary care at least 10 times during the previous year. The main outcome variable is the quality of life measured by the SF-12 questionnaire on Mental Healthcare. Secondary outcome variables include number of consultations, number of drug (prescriptions) and number of days of sick leave together with other prognosis and descriptive variables. Main effectiveness will be analyzed by comparing the percentage of patients that improve at least 4 points on the SF-12 questionnaire between intervention and control groups at 12 months. All statistical tests will be performed with intention to treat. Logistic regression with random effects will be used to adjust for prognostic factors. Confounding factors or factors that might alter the effect recorded will be taken into account in this analysis.
\end{abstract}

\footnotetext{
* Correspondence: alopez.gapm09@salud.madrid.org

${ }^{1}$ Centro de Salud Dr Mendiguchia, Leganés, Madrid, Spain

Full list of author information is available at the end of the article
} 
Discussion: This study aims to provide more insight to address medically unexplained symptoms, highly prevalent in primary care, from a quantitative methodology. It involves intervention group conducted by previously trained nursing staff to diminish the progression to the chronicity of the symptoms, improve quality of life, and reduce frequency of medical consultations.

Trial registration: The trial was registered with ClinicalTrials.gov, number NCT01484223 [http://ClinicalTrials.gov].

\section{Background}

\section{The somatoform disorders}

Somatic symptoms are those symptoms that cannot be medically explained and when they only have a somatic nature, they are referred to as somatoform disorders. They can be found in a healthy population as well as in patients with psychiatric disorders; and they represent an important reason for doctor's examination in primary care. This group of disorders includes [1]: disorder caused by somatization (including 8 symptoms), syndrome by abbreviated somatization (4 symptoms throughout the whole life in men or 6 in women), or multi-somatoform disorder (three or more important symptoms without medical explanation and more than 2 years of development).

The diagnosis of these disorders is difficult. The classification of somatoform disorders in CIE-10 and in DSM IV is shown in Table 1.

Today, there is debate about the suitability of somatization disorder differ from other functional symptoms. It is estimated that $75 \%$ of patients with medically unexplained symptoms (MUS) and over-the health system does not meet the diagnostic criteria for abbreviated somatization syndrome [2]. While somatization disorder affecting $0.4 \%$ of the population, all somatoform disorders are between 20 and $30 \%$ of consultations in primary care [2]. When the patient has at least one symptom in 5 specific areas (pain, fatigue, irritable bowel syndrome, somatic symptoms of anxiety or somatic symptoms of depression) and protracted (at least 4 consultations in a year) some authors recommend defining it as MUS [3].

In a clinical series in the USA, a clear organic cause was not found among the $20 \%-84 \%$ of the patients that went to the family physician with throbs, thoracic pain, migraine, fatigue or sickness [4]. On the other hand, up to $75 \%$ of the patients with major depressive disorders or anxiety attacks go to their family doctors only because of the somatic symptoms they show [5].

A study in Spain [6] shows that 34.5\% of patients who visit for the first time to their family physician suffer from for somatic symptoms. Most of these symptoms are severe, and a percentage end up having a somatization disorder or undifferentiated somatization disorder.

The somatoform disorders are an excluding diagnosis that forces to carry out a significant number of complementary tests and derivations to the second and third level.
The somatoform disorders are highly prevalent in primary care [2]. It is estimated that this kind of patient uses up 14 times more resources in outpatient, and 6 times more expenses under hospital regimen [7].

\section{Approach to the somatoform disorders}

There is consensus that the approach to the different features of somatoform disorders should be carried out with similar interventions; without indicating specific therapies for each of the aforementioned manifestations [8].

There is data on the usefulness of the implementation of Good Clinical Practice (GCP) criteria (Table 2), by the family physician; showing that they can relieve the symptoms, reduce the demand on attention, improve the patients' satisfaction with the given attention and limit the costs; though with modest results [8]. It is important to find tools in the psychosocial approach of these patients added to those already recommended for GCP. The Cognitive Behavioral Therapy (CBT) or the psychodynamic psychotherapy has been useful in the field of secondary medical care [9-11]. In a recent systematic review of the 34 analyzed RCTs on interventions in somatoform symptoms, only 9 are developed in primary care [12]. In these nine RCTs conclude significant results in the decrease of use of services [13-16], improvement on physical and/or psychical performance [17-20]. The reattribution technique specifically designed by Goldberg and Cols [21] is used in two of the analyzed studies for the treatment of somatization in primary care through the teaching and training of family physicians. Their results show low improvement on the physical symptoms [22,23] but there is a significant decrease in the prescription of analgesic medication (8.1\%-23\%) and anti-depressants (11.3\%-26.9\%). The interventions carried out by nursing professionals are effective, but they are excessively expensive in terms of number of sessions (at least 12) and in the required training time (80 hours) [8].

An alternative for the treatment of this kind of disorder in the field of primary care could be group interventions with a limited number of sessions. Martin A et al [24] carry out an RCT that assessed the effectiveness of a single cognitive-behavioral group session (relaxation and motivation technique to take physical exercise) in order to improve the approach of the patient to the symptoms, by means of their explanation from a non- biologist focus. They found a significant reduction in the seriousness of the 
Table 1 Somatoform disorders classification

\begin{tabular}{llll}
\hline & $\begin{array}{l}\text { International Classification } \\
\text { of Diseases, 10th version } \\
\text { (ICD-10) }\end{array}$ & $\begin{array}{l}\text { Diagnostic and Statistical } \\
\text { Manual of Mental } \\
\text { Disorders, 4th Edition } \\
\text { (DSM-IV) }\end{array}$ \\
\hline F45 & Somatoform disorders & Somatoform disorders \\
\hline F45.0 & Somatization disorder & 300.81 & Somatization disorder \\
\hline F45.1 & $\begin{array}{l}\text { Undifferentiated } \\
\text { somatoform disorder }\end{array}$ & 300.82 & $\begin{array}{l}\text { Undifferentiated } \\
\text { somatoform disorder }\end{array}$ \\
\hline F45.2 & $\begin{array}{l}\text { Hypochondriacal } \\
\text { disorders }\end{array}$ & 300.7 & Hypochondriasis \\
\hline F45.3 & $\begin{array}{l}\text { Somatoform } \\
\text { autonomic dysfunction }\end{array}$ & 300.7 & Body Dysmorphic Disorder \\
\hline 30 & $\begin{array}{l}\text { Heart and cardiovascular } \\
\text { system }\end{array}$ & & \\
\hline 31 & $\begin{array}{l}\text { Upper gastrointestinal } \\
\text { tract }\end{array}$ & 307.8 & $\begin{array}{l}\text { Pain Disorder Associated } \\
\text { with Psychological Features }\end{array}$ \\
\hline 32 & $\begin{array}{l}\text { Lower gastrointestinal } \\
\text { tract }\end{array}$ & 300.11 & Conversion Disorder \\
\hline 34 & $\begin{array}{l}\text { Genitourinary system } \\
\text { 38 }\end{array}$ & Other organ or system & \\
\hline F45.4 & $\begin{array}{l}\text { Persistent somatoform } \\
\text { pain disorder }\end{array}$ & \\
\hline F45.8 & $\begin{array}{l}\text { Other somatoform } \\
\text { disorders }\end{array}$ & \\
\hline F45.9 & $\begin{array}{l}\text { Somatoform disorder, } \\
\text { unspecified }\end{array}$ & \\
\hline
\end{tabular}

symptoms, in the number of consultation to the family physicians (not in the visits to the specialist), reduction in number of drug (prescriptions) and in the number of days on sickness absence. This intervention was carried out by mental health professionals, which limits its external validity and its implementation in the field of primary care.

A correct approach to these patients by their family doctor may reduce iatrogenic. The training of primary care professionals can help to improve care for patients consulting for MUS.

A model on cognitive-behavioral group intervention, based on reattribution techniques, carried out through four group sessions by primary care nurses, together with the implementation of regulations on GCP, would be effective for improving quality of life of patients with MUS.

\section{Aims}

The aim of the present work is to determine whether a cognitive-behavioral intervention group in patients between 18 and 65 years old with medically unexplained symptoms, is more effective than routine clinical practice to improve the quality of life measured by SF- 12 questionnaire at one year follow-up.

The secondary objectives are to determine whether a cognitive-behavioral intervention group with medically unexplained symptoms, is more effective than routine clinical practice to:

- Improve the quality of life measured by SF-12 questionnaire at 3 and 6 months.

- Reduce the drug consumption.

- Reduce the number of medical consultation.

- Reduce the days of sickness absence.

- Raise the perception on improvement (standardized global vision) from the patient's point of view (PGI-I questionnaire) and from the doctor's (with the CGI-I).

\section{Methods/Design \\ Design of the study}

This study is a community, parallel clinical trial, randomised by clusters, that compares cognitive-behavioral intervention group with routine clinical practice. The intervention will be carried out by health professionals in 14 Primary Health Care Centres (PHCCs), in Madrid (Spain).

The randomization units will be the PHCCs (clusters). The units of analysis will be the patients between 18 and 65 years old with MUS who have seeked medical attention in PHCCs at least 10 times over the past year. The design by clusters minimised possible contamination effects between centres.

\section{Subjects of the study}

Adult patients between 18 and 65 years old with MUS, defined by the occurrence of two or more symptoms during the last 6 months without any evidence of organic disease that could explain them, and who have seeked medical attention in primary care at least 10 times during the last year.

1) Inclusion criteria. All patients were required to be:

a. Be able to meet the demands inherent to the trial, i.e, to have no intention of moving, to be reachable for the next year, and to have the capacity to understand the questionnaires presented

b. Give signed informed consent to be included in the study, and to meet no exclusion criterion.

\section{2) Exclusion criteria.}

a. Diagnosis of severe mental disorder.

b. Suicidal ideation at the time involved in the study.

c. Diagnosis of addiction to toxic substances.

d. Diagnosis of organic disease responsible for the symptoms.

e. Previous psychotherapy during the previous year.

\section{Randomisation}

The randomization unit will be the PHCC. An independent statistician will randomly assign the 14 PHCCs (7 centres 


\begin{tabular}{l}
$\begin{array}{l}\text { Table } \mathbf{2} \text { Regulations on good clinical practice in the general approach of the patient with medical unexplained } \\
\text { symptoms }\end{array}$ \\
\begin{tabular}{ll}
\hline 1. & $\begin{array}{l}\text { To plan regular appointments every } 4-6 \text { weeks in order to treat them clinically during the first year / } 6 \text { months, or if a new symptom } \\
\text { comes up (in worsening periods, appointments could be more frequent). }\end{array}$ \\
\hline 2. & To give the patient a detailed document on the origin of the symptoms \\
\hline 3. & To establish high-priority objectives \\
\hline 4. & To restrict complementary examinations to the most indispensable ones \\
\hline 5. & To control the visits to specialists \\
\hline 6. & To have the patient treated by only one doctor \\
\hline 7. & To calm down and to reassure \\
\hline 8. & To identify the psychosocial stimuli that are involved as well as their link to the worsening of the symptomatology \\
\hline 9. & To avoid ambiguous information about the findings that come up \\
\hline 10. & To avoid spurious diagnostics \\
\hline 11. & Not to treat what the patients do not suffer from \\
\hline 12. & To avoid dichotomy explanations, i.e. (mental-physical nature) \\
\hline 13. & To mediate, when possible, in their psychosocial problems \\
\hline 14. & The best policy is to be sincere on the reports \\
\hline 15. & To approach some problems in a multidisciplinary way \\
\hline 16. & To organize the management/treatment of the difficult cases \\
\hline 17. & To be consistent with the approaches \\
\hline 18. & To properly remit to the psychiatry services \\
\hline
\end{tabular} \\
\hline
\end{tabular}

in each group) to either the intervention group or a control group following a simple, computer-generated random sequence (Epidat 3.1 software).

Consecutive patients will be chosen to minimize the risk of bias in their selection.

During consultations, patients will be informed about the study and asked whether they would like to take part. Those who accept will be asked to give their signed consent, and checks were made to ensure they met all inclusion criteria but no exclusion criteria.

\section{Sample size}

Method of calculation For an alpha of 0.05, a power of $80 \%$, and in order to detect an increase of $20 \%$ in the proportion of patients that improve at least 4 points on area of mental healthcare of the SF-12 questionnaire $(50 \%$ in the intervention group and 30\% in the control group), the overall sample size required is 206 patients (103 in each arm of the study).

Since randomization is by clusters, the sample size had to be larger than if simple randomisation had been performed, in order to take into account the design effect. The intra-class correlation coefficient is $0.01[25,26]$ and a mean cluster size is assumed to be 8 patients. The design effect is 1.07. Given these assumptions, and expecting a $10 \%$ loss rate at one year, the final sample size required is 242 (121 in each arm).

\section{Masking}

In a study of this type it is impossible to mask the intervention. The analysis data will be performed by independent professionals blinded to the assignment group.

Intervention:

\section{a. In the control group:}

Routine clinical practice: The clinical approach of the patients will be done following the recommendations of clinical practice guidelines as detailed in Table 2.

\section{b. In the intervention group:}

Besides the routine clinical practice, four weekly cognitivebehavioral group sessions of 2 hours guided by nurse professionals will be carried out in the PHCC. The groups will be made up by $6-12$ patients.

The content of the sessions will be as follows (Table 3):

If the study results prove that the intervention is effective, cognitive behavioral sessions are planned for the patients in the control group.

Before starting the intervention itself, will develop the training for professionals involved in the study. In order to make the best use of the diagnosis and the therapeutic approach on the patients that have been identified as suffering from anxiety and/or depression disorders, and to standardize clinical practice, a two-hour initial training 


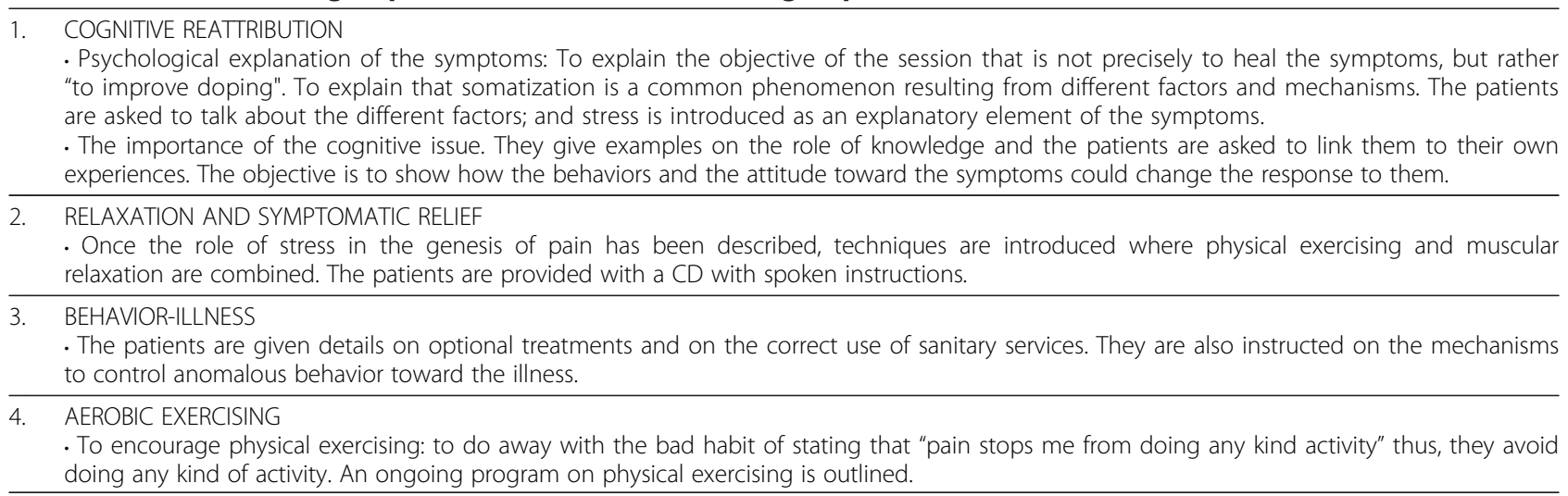

session will be carried out for all the doctors that participate in the study. The session will have the following content: train in the use of the PRIME-MD questionnaire; as well as in upgrading the rules on pharmacological treatment of the detected pathologies. In addition will be reviewed Standards for GCP for approaching the patients with MUS (Table 2).

Besides, there will be a ten-hour specialized training session aimed to the nurses in charge of perform the intervention at each center, reattribution techniques and cognitivebehavioral, that underlie the intervention group.

\section{Data collection method}

The doctor will recruit the patients and will assess the selection criteria. He will let the patient know about the objectives of the study; and will request his informed consent.

All patients who accepted to participate will get the SF-12 questionnaire on quality of life at the end of the doctor's examination. Furthermore, all patients will get the PRIME-MD questionnaire to identify any psychiatric co-morbidity that will be treated by the doctor according to his criterion.

At 3, 6 and 12 months (visits V2, V3 and V4, respectively) will be referred the patient to evaluate the usefulness of cognitive-behavioral sessions, and completion of quality of life questionnaire (SF-12) and Clinical Global Impression of patient and physician (PGI and CGI).

The structure of the study is described in Table 4.

\section{Variables}

\section{Outcomes variables}

The main outcome variable is the improvement in 4 or more points in the area of Mental Healthcare from the SF12 Quality of life at 12 months. The Spanish version of this Questionnaire has been validated: high inner consistency (range 0.77-0.92) for all the dimensions, except social function (0.55). The questionnaire is self-administered.
The secondary outcome variables recorded are:

- Questionnaire on Global Clinical Impression. Used to assess the patient's (PGI questionnaire) and the doctor's (CGI Questionnaire) perceptions on the its improvement with the interventions. Will be administered at 6 months (to assess the effectiveness of the rules of good clinical practice) and at 12 months to evaluate the effectiveness of the intervention group added to the standards of good clinical practice. Will be treated as ordinal qualitative variable.

- Quality of life at 3 and 6 months after the intervention measured by the SF-12 questionnaire.

- Number of consultations during the period of study (broken down between nursing and medicine, each group session will be counted as a nursing consultation).

- Prescribed medicine during the period of study, with doubtful therapeutic value for their processing; related to the MUS. The included medicines are those related to the functional symptomatology:

- Pain: analgesic medicines, Nonsteroidal Antiinflammatory Drugs and muscular pain reliever.

- Dizziness: vestibular sedatives, peripheral brain and vasodilators.

- Digestive Symptoms: pro-kinetics, anti-emetics.

- Asthenia: vitamin complex, restoratives, derived from ginseng, appetite stimulants.

- Anxiety: anxiolytics, antidepressants.

It will be regarded as quantitative variable, defined as the number of medicine taken during the period of study.

- Days of sickness absence during the period of study. 
Table 4 Project structure

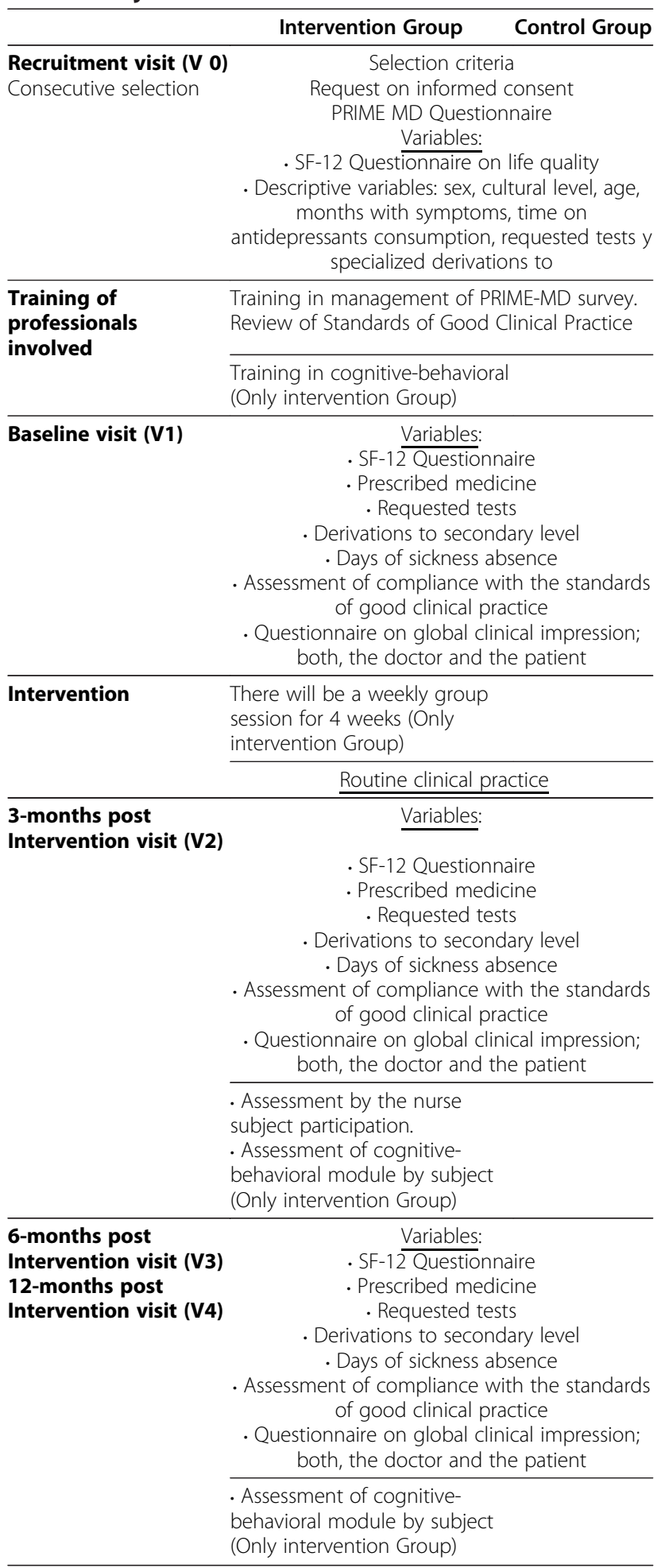

\section{Clinical Variables}

- Duration of the somatic symptoms before the study. Quantitative variable (number of months).
- Time on anti-depressants consumption (months) before the study.

- Psychiatric Co-morbidity at the beginning of the study. It will be analyzed as a dichotomy qualitative variable (yes/no); assessing the presence/absence of depression, anxiety and somatic-morph disorders (according to the PRIME MD classification).

- PRIME-MD questionnaire; validated in Spain [27] that categorizes the patient into 5 areas of mental disorders with greater incidence on primary care: disorders in the state of mind/mood, anxiety disorders, disorders on nutritional behavior, somatoform disorders and disorders due to alcohol abuse or addiction. There are two components: a questionnaire for the patient that acts as a sifting/testing tool, and an assessment guide for the doctor that allows the diagnostic confirmation on the case. Once the questionnaire has been carried out, the patients diagnosed under anxiety or depression will be treated in a standardized way. Thus a bias is eliminated in the understanding of the study results, i.e. not to have treated the identified anxious-depressive

psychiatric co-morbidity in a proper way; an issue that could have positive effect on the somatoform manifestations.

- Derivations carried out at secondary level.

- Complementary Tests, grouped in the following categories: laboratory, image tests, and endoscopies.

\section{Sociodemographics descriptive variables}

Age, sex, cultural level, labor status on date of inclusion into the study.

\section{Withdrawal}

Subject withdrawal criteria

a. The appearance of a pathological condition to explain the symptoms.

b. The use of an unusual alternative therapy (other than those normally used by the patient) for the treatment of symptoms, such as psychotherapy, etc. that could alter the outcome.

c. If the patient shows his/her desire to withdrawing from the study.

d. If the patient does not come to the follow-up visits.

If any of these events take place, it will be registered on the Case Report Form (CRF); stating clearly the date and the reason. The data will be equally processed to allow the analysis with intention to treat. 


\section{Statistical Analysis}

The use of randomization by clusters conditions the statistical analysis that can be employed, especially in the calculation of confidence intervals and the testing of hypotheses. The following analyses will be undertaken:

1. Descriptive analysis of each variable with its corresponding CI at 95\%. Description of the profile of patients who abandoned the study plus their reason for withdrawal.

2. Baseline comparison of the two intervention groups in terms of the variables measured, prognostic factors and descriptive variables. Bivariate statistical tests will be used depending on the type of variable (qualitative or quantitative one).

3. Analysis of primary outcome: comparison of the proportion of patients that improve in 4 or more points in the area of Mental Healthcare from the SF-12 in both groups, at 12 months after patient inclusion, using the Chi-squared test, and the calculation of confidence intervals 95\%. Logistic regression with random effects will be used to adjust for prognostic factors; the dependent variable will be the improvement or not in 4 or more points obtained in Mental Healthcare; and the independent variable the intervention group to which each patient belonged. Confounding factors or factors that might alter the effect recorded will be taken into account in this analysis.

4. Analysis of secondary outcomes variables. The results of the secondary variables according to the assigned group will be compared for each secondary response variable using appropriate statistical tests.

All statistical tests will be performed with intention to treat. The last observation carried forward will be used for missing data. Significance was set at $p<0.05$. All calculations will be made using SPSS $\odot$ v.18 software.

\section{Ethical considerations}

The study protocol was approved by the Research Ethics Committee on October, $29^{\text {th }} 2008$ and met all good clinical practice demands right. This study has been funded by the Spanish Ministry of Science and Innovation via the Instituto de Salud Carlos III (PI08/90707). The trial was registered with ClinicalTrials.gov, number NCT01484223 [http://ClinicalTrials.gov].

\section{Discussion}

Resolute treatment of psychological or psychosocial issues by primary care professionals is a encouraging challenge. The study incorporates the PRIME MD questionnaire, a useful tool for diagnosing comorbid conditions. The time for application is 10 minutes. Its sensitivity and specificity make it a valid tool for the diagnosis of the most prevalent psychiatric disorders in primary care.

The study design used in this work is, however, subject to certain limitations. The intervention cannot be masked, which could influence the assessment of its effect. Certainly, the possibility of contamination exists if the patients or professionals involved communicate with one another. For this reason randomization by clusters was employed. It was assumed that the number of clusters was sufficient for the random assignment of PHCCs to one arm or the other to compensate for such potential confounding factors.

To mask the analysis of data, the persons charged with this task were blind to the arm to which each health care center had been assigned.

\section{Abbreviations \\ CBT: Cognitive behavioral therapy; CGl: Clinical global impression; ICD: International statistical classification of diseases and related health problems; CRF: Case report form; DSM-IV: Diagnostic and statistical manual, mental disorders-IV; GCP: Good clinical practice; PGI: Patient global impression; PHCC: Primary healthcare centre; PRIME-MD: Primary care evaluation of mental disorders; RCT: Randomized controlled trial; SF-12: Short-form health status measures-shorter. \\ Competing interests \\ This manuscript contains no information on medical devices. The authors received, nor will receive, individual financing of their work.}

\section{Acknowledgements}

To Yolanda Rodriguez for her contribution to the administrative support.

\begin{abstract}
Author details
${ }^{1}$ Centro de Salud Dr Mendiguchia, Leganés, Madrid, Spain. ${ }^{2}$ Unidad de Apoyo a la investigación, Gerencia de Atención Primaria, Madrid, Spain. ${ }^{3}$ Facultad de Ciencias de la Salud, Universidad Rey Juan Carlos, Alcorcón, Madrid, Spain. ${ }^{4}$ Hospital Puerta de Hierro, Majadahonda, Madrid, Spain. ${ }^{5}$ Facultad de psicología, Universidad de Educación a Distancia, Madrid, Spain. ${ }^{6}$ Centro de Salud M, Ángeles López Gómez, Leganés, Madrid, Spain. 7 Escuela Nacional de Sanidad, Instituto de Salud Carlos III, Madrid, Spain. ${ }^{8}$ Centro de Salud Huerta de los Frailes, Leganés, Madrid, Spain. ${ }^{9}$ Centro de Salud Maria Jesús Hereza, Leganés, Madrid, Spain. ${ }^{10}$ Centro de Salud Argüelles, Madrid, Spain. ${ }^{11}$ Facultad de ciencias biosanitarias, Universidad Francisco de Vitoria, Pozuelo de Alarcón, Madrid, Spain. ${ }^{12}$ Centro de Salud Castilla la Nueva, Fuenlabrada, Madrid, Spain. ${ }^{13}$ Centro de Salud Cuzco, Fuenlabrada, Madrid, Spain. ${ }^{14}$ Centro de Salud Boadilla, Boadilla del Monte, Madrid, Spain. ${ }^{15}$ Centro de Salud Pozuelo Estación, Pozuelo de Alarcón, Madrid, Spain. ${ }^{16}$ Centro de Salud Sierra de Guadarrama, Collado Villalba, Madrid, Spain. ${ }^{17}$ Centro de Salud Francia, Fuenlabrada, Madrid, Spain. ${ }^{18}$ Centro de Salud Loranca, Fuenlabrada, Madrid, Spain. ${ }^{19}$ Centro de Salud Valdezarza, Madrid, Spain.
\end{abstract}

\section{Authors' contributions}

ALGF conceived of the study, participated in its design and coordination of the study. IDC, TSC, LC, and MIDG (senior authors) participated in the design of the study. ALGF, IDC, TSC, MTRM, PL and MC directed the writing of the manuscript. Contributions were made by the remaining authors. All authors read and approved the final manuscript. 
PHCC María Ángeles López Gómez "Pedroches" (Leganés): Teresa Rodríguez Monje, Mercedes Fernández Girón, Liliana Losada Cucco, Jeanette Sánchez López, Beatriz López Serrano, María Cortés Durán. Dolores Serrano, Rafaela Ayllón Camargo, Imma Santamaría López.

PHCC Cuzco (Fuenlabrada): Ma Ángeles Miguel Abanto. Teresa Sanz Bayona, Teresa López Martin-Aragón

PHCC Castilla la Nueva (Fuenlabrada): María Santiago Hernando, Carlos Díaz Gómez Calcerrada, Guadalupe García Caro. Monserrat Jurado Sueiro, Manuela Luque Rey.

PHCC Boadilla del Monte (Boadilla del Monte): Ma Fe Prádana Martínez, Lourdes Del Santo Mora, Ángeles García Pindado, Nuria Ruiz Hombrebueno. Rosario Beltrán Álvarez, Ana Isabel Aguilar Gutiérrez, José Luis Mota Rodríguez, Rafael Cosculluela Pueyo.

PHCC Pozuelo Estación (Pozuelo de Alarcón): José Maa Fernández-Bravo Álvarez, María Lacalle Rodríguez-Labajo, Diana Pitarch Velasco, Celia García López, Irene Ayuso Olmedo. Rosa Bonilla Sánchez, Maª Carmen ArtiedaGonzález-Granda, Raquel Razola Rincón.

PHCC Sierra de Guadarrama (Collado Villalba): Ma Gloria Heras Salvat. M Ángeles Sánchez de la Ventana, Concepción Martínez Guinea, Luis Huerta Galindo, Ana Belén Barrio Ovalle, Susana Miguel Martin, Paz Portero Fraile. PHCC Ma Jesús Hereza (Leganés): Teresa Rollán Landeras, Ma Jesús Bedoya Frutos, Ma Angeles Rollán Hernández.

PHCC Huerta de los Frailes (Leganés): Inmaculada Muñoz Sánchez, Francisco Gutiérrez Ruiz, Susana Menéndez Álvarez.

PHCC Francia (Fuenlabrada): Julia Sánchez Miró. Higinio Pensado Freire (HP)

PHCC Loranca (Fuenlabrada): Arturo Rodríguez Cardoso, Ma José Rojas Giraldo. Marisa Herrera Garcia.

PHCC Valdezarza (Madrid): Eva Muro Díaz, Dolores Reguera de Castro, Paloma Rius Fortea. Inés Gómez García, Nuria Llamas Sandino, Isabel López Borja, Hortensia Maldonado Castro.

PHCC Villanueva de la Cañada (Villanueva de la Cañada): Cristina López Menéndez, Juana Blasco Albert.

PHCC Pozuelo San Juan (Pozuelo de Alarcón): Alicia Díaz Revilla, Fernando León Vázquez, Pilar Burón Martínez, Beatriz Fandiño García, Pedro Pablo Iglesias Dorado, Ma José Rey Álvarez.

Received: 23 December 2011 Accepted: 2 May 2012

Published: 2 May 2012

\section{References}

1. American Psychiatric Association: Diagnosis and statistical manual of mental disorders. IVthth edition. Washington: American Psychiatric Press; 1994.

2. Smith RC, Lein C, Collins C: Treating patients with medically unexplained symptoms. Psychosom Med 2005, 67:123-129.

3. Robbins JM, Kirmayer $L$, Hemani S: Latent variable models of functional somatic distress. J Nerv Ment Dis 1997, 185:606-615.

4. Barsky AJ, Stern TA, Greenberg DB: Functional somatic symptoms and somotoform disorders. In Massachusetts General hospital Handboook of General Hospital Psychiatry. Fourth edth edition. Edited by Cassem NH, Stern TA, Rosembaun. St Louis: Mosby; 1997.

5. Kirmayer $L$, Robbins $J \mathrm{M}$ : Three forms of somatization in primary care: prevalence, co-occurrence, and sociodemographic characteristics. J Nerv Men Dis 1991, 179(11):647-655.

6. García-Campayo JJ, Campos R, Pérez Echevarría MJ, Lobo A, GEMPPZ: Somaticers and psychologizers in primary care. 150 Annual meeting of the American Psychiatric Association. PhiladelPhia 1994, :21-26. mayo.

7. Smith GR, Monson RA, Ray DC: Patients with multiple unexplained symptoms. Their characteristics functional health and health care utilization. Arch Intern Med 1986, 146:69-72.

8. Smith RC, Lyles JS, Gardiner JC, Sirbu C, Hodges A, Collins C, et al: Primary care clinicians treat patients with medically unexplained symptoms: a randomized controlled trial. J Gen Intern Med 2006, 21:671-677.

9. Smith GR: Somatization Disorders in the medical setting. Washington: American Psychiatric Press; 1991.

10. Sumathipala $A$ : What is the evidence for the efficacy of treatment for somatoform disorders? A critical review of previous intervention studies. Psychosom Med 2007, 69(9):889-900.

11. Kroenke K, Swindle R: Cognitive behavioral therapy for somatization and symptoms syndromes: a critical review of controlled clinical trials. Psychother Psychosom 2000, 69:205-215.
12. Kroenke K: Efficacy of treatment for somatoform disorders: a review of randomized controlled trials. Psyshosom Med 2007, 69(9):881-888.

13. Smith GR, Monson RA, Ray DC: Psychiatric consultation in somatization disorder, controlled study. N Engl J Med 1986, 314:1407-1413.

14. Allen LA, Woolfolk RL, Escobar JL, Gara MA, Hammer RM: Cognitivebehavioral therapy for somatization disorder: a randomized controlled trial. Arch Inter Med 2006, 166(14):1512-1518.

15. Escobar JL, Gara MA, Díaz Martínez AM, Interian A, Warman M, Allen LA, et al: Effectiveness of a time limited cognitive behaviour therapy type intervention among primary care patients with medically unexplained symptoms. Ann Fam Med 2007, 5(4):328-335.

16. Rief W, Martin A, Rauh E, Zech T, Bender A: Evaluation of general practitioner's training: how to manage patients with unexplained physical symptoms. Psychosomatics 2006, 47:304-311.

17. Dickinson WP, Dickinson LM, De-Gruy FV: A randomized clinical trial of a care recommendation letter intervention for somatization in primary care. Ann Fam Med 2003, 1:228-235.

18. Rost K, Kashner TM, Smith GR: Effectiveness of psychiatric intervention with somatization disorder patients: improved outcomes at reduced cost. Gen Hosp Psychiatry 1994, 16:381-387.

19. Smith GR, Rost K, Kashner TM: A trial of the of a standardized psychiatric consultation on health outcomes and cost in somatising patients. Arch Gen Psychiatry 1995, 52:238-243.

20. Sumathipala A, Hewege S, Hanwella R, Mann AH: Randomised controlled trial of cognitive behaviour therapy for repeated consultations for medically unexplained complaints: a feasibility study in Sri Lanka. Psychol Med 2000, 30:747-757.

21. Goldberg DP, Gask L, O'Dowd T: The treatment of somatization: teaching techniques of reatribution. J Psychosom Res 1989, 33:689-695.

22. Rosendal $M$, Olesen F, Fink P, Toft T, Sokolowski I, Bro F: A randomized controlled trial or brief training in the assessment and treatment of somatization in primary care: effects on patient outcome. GenHosp Psychiatry 2007, 29(4):364-373.

23. Larisch A, Schweickhardt A, Wirsching M, Fritzsche K: Psycohsocial interventions for somatizing patients by the general practitioner: a randomized controlled trial. J Psychosom Res 2004, 57:507-514.

24. Martin A, Rauh E, Fitcher M, Rief W: A one session treatment for patients suffering from medically unexplained symptoms in primary care: a randomized clinical trial. Psychosomatics 2007, 48:294-303.

25. Silva C: Muestreo estratificado polietápico. In Diseño razonado de muestras y captación de datos para la investigación sanitaria. Edited by de Santos Diaz. Madrid:; 2000:332.

26. Adams G, Gulliford MC, Ukoumunne OC, Eldridge S, Chinn S, Campbell MJ: Patterns of intra-cluster correlation from primary care research to inform study design and analysis. J Clin Epidemiol 2004, 57:785-794.

27. Vaca E, Saiz J, Aguera LF, Caballero L, Fenández Liria A, Ramos JÁ, et al: Prevalencia de trastornos mentales en atención primaria usando el cuestionrio PRIME-MD. Aten Primaria 1999, 23:275-279.

doi:10.1186/1471-2296-13-35

Cite this article as: López-García-Franco et al:: Effectiveness of a cognitive behavioral intervention in patients with medically unexplained symptoms: cluster randomized trial. BMC Family Practice 2012 13:35

\section{Submit your next manuscript to BioMed Central and take full advantage of:}

- Convenient online submission

- Thorough peer review

- No space constraints or color figure charges

- Immediate publication on acceptance

- Inclusion in PubMed, CAS, Scopus and Google Scholar

- Research which is freely available for redistribution 